\title{
Complete remission of stage IV sinonasal small cell neuroendocrine carcinoma: A case report
}

\author{
ALBERTO RAPOSO ${ }^{1}$, MARÍA JOSÉ MARTÍNEZ-ORTIZ ${ }^{2}$, ANA BUENDÍA ${ }^{3}$, \\ ELENA GUILLÉN $^{4}$, CRISTINA BERMÚDEZ ${ }^{5}$ and FRANCISCO GARCÍA-PURRIÑOS ${ }^{1}$
}

\begin{abstract}
${ }^{1}$ Department of Otorhinolaryngology-Head and Neck Surgery, Hospital Universitario Los Arcos del Mar Menor, San Javier, 30739 Murcia; ${ }^{2}$ Department of Medical Oncology, Hospital Universitario Santa Lucia, Cartagena, 30202 Murcia; ${ }^{3}$ Department of Anatomical Pathology, Hospital Universitario Los Arcos del Mar Menor, San Javier, 30739 Murcia; ${ }^{4}$ Department of Anatomic Pathology, Hospital Universitario Santa Lucia, Cartagena, 30202 Murcia;

${ }^{5}$ Department of Radiology, Hospital Universitario Los Arcos del Mar Menor, San Javier, 30739 Murcia, Spain
\end{abstract}

Received August 3, 2021; Accepted September 30, 2021

DOI: $10.3892 / \mathrm{mco} .2021 .2481$

\begin{abstract}
Sinonasal small cell carcinoma $(\mathrm{SmCC})$ is a rare type of neoplasm. The current case report describes the case of a 30-year-old male patient with stage IV SmCC who underwent concurrent radiotherapy (RT) plus etoposide-cisplatin treatment. Positron emission tomography (PET)/computed tomography (CT) and fibroscopy examination showed complete remission at 3 months post-treatment. However, leptomeningeal metastasis (LM) occurred at 9 months. A literature search identified no previous case reports describing LM of SmCC. The patient was treated with concurrent RT plus irinotecan-gemcitabine. During the sixth cycle of irinotecan-gemcitabine, the patient required intensive care admission due to severe acute respiratory syndrome-related coronavirus 2-associated pneumonia. Following clearance of the pneumonia, LM was assessed using PET/CT and MRI at 3 months, which revealed a complete response to irinotecan-gemcitabine. In May 2021, the patient succumbed to LM following disease recurrence. The findings of this case report should encourage other authors to publish their treatment outcomes regarding SmCC. More clinical trials are required to achieve better results in terms of patient outcome.
\end{abstract}

\section{Introduction}

Sinonasal small cell carcinoma (SmCC) is a subtype of sinonasal neuroendocrine carcinoma (SNEC). Until 2013, only

Correspondence to: Dr Alberto Raposo, Department of Otorhinolaryngology-Head and Neck Surgery, Hospital Universitario Los Arcos del Mar Menor, 1 Torre Octavio Street, San Javier, 30739 Murcia, Spain

E-mail: albertoraposojimenez@gmail.com

Key words: sinonasal small cell carcinoma, severe acute respiratory syndrome-related coronavirus 2-associated pneumonia, leptomeningeal metastasis, etoposide-cisplatin, irinotecan-gemcitabine
76 cases of SmCC had been reported in the literature (1). In 2016, a study by Van der Laan et al (2) published the cases of 115 patients with SmCC. An analysis of the National Cancer Database performed by Pointer et al (3) described 162 cases of SmCC. Smoking is known to be associated with aggressive SmCC and the median survival for SmCC is 22 months $(2,3)$.

The histological subtypes of SNEC depend on the differentiation grade and include poorly differentiated small cell SmCC, poorly differentiated or undifferentiated large cell SNEC and well to moderately differentiated SNEC (2). Diagnosis of the SmCC subtype requires positivity for certain immunohistochemical markers, such as CD55 and thyroid transcription factor-1 (TTF-1). Positive synaptophysin or chromogranin A expression may also be present, but these markers are not required for diagnosis. Positive Ki-67 protein expression is also used as a cell proliferation marker for $\operatorname{SmCC}(4,5)$.

The treatment response of patients with SmCC depends on the stage, differentiation grade and proliferation rate (6). It is known that stage IV disease, poor differentiation and high cell proliferation rate predict a worse treatment response $(6,7)$. It has been suggested that radiotherapy (RT) may be the most effective treatment option for these patients $(2,4)$. However, other studies and the guidelines issued by the French Cervico-facial Carcinological Society have indicated that etoposide plus cisplatin may be the best treatment option $(1,3,6,7)$. Currently, no consensus has been reached regarding the optimal treatment approach to SmCC (8). Irinotecan plus gemcitabine can be used as second-line therapy for relapsed or refractory small cell carcinoma $(9,10)$.

SmCC has a poor prognosis; according to Pointer et al (3), the median survival time of patients with SmCC is 36.4 months. Another systematic review of 80 patients with SmCC revealed a survival rate of $46.3 \%$ after a mean follow-up of 30.8 months, whereby $43.1 \%$ of the patients succumbed to the disease due to metastasis and $5.6 \%$ due to other causes (8).

\section{Case report}

The current case report presents the case of a 30-year-old male patient with diabetes, who was a smoker (20 cigarettes/day) 
and a fisherman by profession; the patient presented with daily headaches and mild recurrent episodes of unilateral epistaxis from the left nostril that had persisted for 40 days. The patient attended Los Arcos del Mar Menor University Hospital (Murcia, Spain). Fibroscopy examination performed in September 2019 showed an exophytic pink mass in the left nasal cavity. Cervical and paranasal sinus computed tomography (CT) performed 5 days later revealed a mass in the left maxillary sinus extending to the nasal cavity, ethmoidal sinus, sphenoid sinus, cribriform plate, lamina papyracea, posterior intraconal orbital space and left jugular foramen. A sinonasal biopsy was taken under topical anesthesia. Immunohistochemistry was subsequently performed. Paranasal tissues were fixed in $10 \%$ formalin at room temperature $\left(26^{\circ} \mathrm{C}\right)$ for $24 \mathrm{~h}$. The tissues were then paraffin-embedded $\left(60^{\circ} \mathrm{C}\right)$, cut into $2.5-\mu \mathrm{m}$ sections and introduced in an integrated staining and mounting system (Tissue Tek Prisma ${ }^{\circledR}$ Plus-Tissue Tek Film ${ }^{\circledR}$; Sakura Finetek USA) for $45 \mathrm{~min}$ at $26^{\circ} \mathrm{C}$, followed by deparaffinization with xylene, rehydration in various grades of alcohol (100\% up to distilled water), staining with Harris hematoxylin (9 min at $26^{\circ} \mathrm{C}$, followed by rinsing in distilled water), staining with eosin yellow $\left(8 \mathrm{~min}\right.$ at $\left.26^{\circ} \mathrm{C}\right)$, dehydration in various grades of alcohol (70\% up to $100 \%$ ), and mounting in xylene-based medium (DPX-Tissue Tek ${ }^{\circledR}$ Coverslipping film; Sakura Finetek USA). The sections were subsequently incubated with primary antibodies against CD56, TTF-1, chromogranin A, synaptophysin and Ki67. The duration of the incubation of these antibody incubations ranged between 12 and 16 min at $36-37^{\circ} \mathrm{C}$. Sections were visualized under a light microscope (magnification, x40). Anti-CD56 (1:125; cat. no. 123C3, Roche Diagnostics) exhibited intense membrane positivity in $100 \%$ of the tumor cells. Anti-TTF-1 (1:175; cat. no. SP141, Roche Diagnostics) exhibited intense nuclear positivity in $100 \%$ of the tumor cells. Anti-chromogranin A (1:1,000; cat. no. LH2H10, Roche Diagnostics) staining was negative. Anti-synaptophysin (1:200; cat. no. SP11, Roche Diagnostics) staining was negative. Anti-Ki-67 (1:500; cat. no. 30-9, Roche Diagnostics) was positive in $90 \%$ of the tumor cells. Immunohistochemistry examination demonstrated neuroendocrine marker CD56 (Fig. 1) and TTF-1 (Fig. 2) positivity. Sinonasal biopsy revealed an SmCC.

Metastasis was ruled out by positron emission tomography (PET)/CT (cT4N0M0). In October 2019, RT plus etoposide-cisplatin was administered as the first-line treatment. A total of 50 Gy was delivered in 25 daily fractions of RT. The patient received four cycles (every 21 days) of cisplatin $\left(100 \mathrm{mg} / \mathrm{m}^{2} ; \mathrm{IV}\right)$ and etoposide $\left(100 \mathrm{mg} / \mathrm{m}^{2} ; \mathrm{IV}\right)$ on day 1 , followed by etoposide $\left(200 \mathrm{mg} / \mathrm{m}^{2}\right)$ on days $2-3$. PET/CT and fibroscopy confirmed complete remission in March 2020. The patient was evaluated every 2 months according to the National Comprehensive Cancer Network (11). Subsequently, 5 months later, the patient underwent lumbar MRI due to lumbar back pain that had persisted for $>3$ weeks, which revealed leptomeningeal metastasis (LM) in the medullary cone. In September 2020, the patient received palliative RT (20 Gy in 5 fractions) plus six cycles (every 21 days) of irinotecan $\left(100 \mathrm{mg} / \mathrm{m}^{2} ; \mathrm{IV}\right)$ on days $1-8$ and gemcitabine $\left(1,000 \mathrm{mg} / \mathrm{m}^{2} ; \mathrm{IV}\right)$. During the sixth cycle of irinotecan-gemcitabine (October 2020), the patient was admitted to intensive care due to severe acute respiratory syndrome-related coronavirus 2 (SARS-Cov-2)-associated

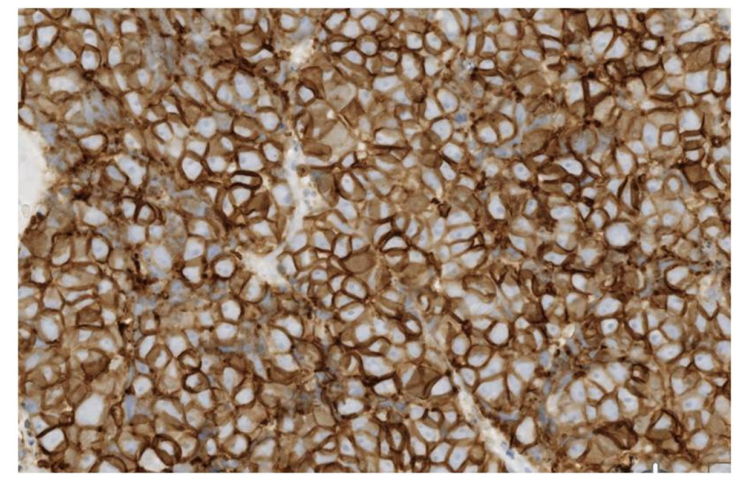

Figure 1. Immunohistochemical examination revealed that the tumor was positive for CD56 expression (magnification, $\mathrm{x} 40$ ).

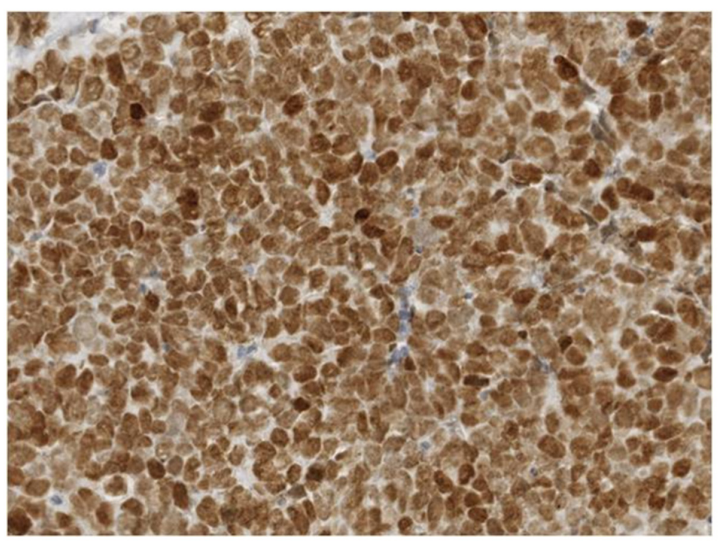

Figure 2. Immunohistochemical examination revealed that the tumor exhibited strong nuclear staining for thyroid transcription factor-1 (magnification, $\mathrm{x} 40)$.

pneumonia. A total of 3 months after the clearance of the pneumonia, LM was assessed using PET/CT, and a complete response to irinotecan-gemcitabine was confirmed. However, in May 2021, the patient succumbed to the disease following LM recurrence.

\section{Discussion}

The present case study reports an extremely rare and aggressive carcinoma of the paranasal sinuses with an unusual site of metastasis. Literature searches reveal few reported cases of SmCC. In the present study, three Anatomical Pathology Units at different public hospitals in Murcia were required to confirm the histological diagnosis of SmCC. In the present case report, immunohistochemical staining for chromogranin A and synaptophysin was negative, while staining for CD56, TTF-1 and Ki-67 (90\%) was positive (5,7). The three Anatomical Pathology Units reached the same histological diagnosis.

The Head and Neck Tumors Committee of Los Arcos del Mar Menor University Hospital considered RT plus chemotherapy to be the most appropriate treatment instead of nasal surgery based on the result of an analysis of the National Cancer Database published in 2017, in which it was stated that nasal surgery did not improve the survival rate of patients with stage IV SmCC (3). At present, there are no 
clear guidelines regarding SmCC treatment. Only 30 articles were found in the PubMed database using the keywords 'sinonasal' AND 'small cell carcinoma' AND 'treatment' (https://pubmed.ncbi.nlm.nih.gov/?term $=\% 22$ sinonasal\%22 +AND+\%22Small+Cell+Carcinoma\%22+AND+\%22+Treat ment\%22). The limited number of reports on $\mathrm{SmCC}$ in the literature could be one of the reasons for the lack of treatment guidelines. Three articles were found in the PubMed database using the keywords 'leptomeningeal metastasis' AND 'neuroendocrine carcinoma', but no articles were found using the keywords 'leptomeningeal metastasis' AND 'small cell carcinoma' (https://pubmed.ncbi.nlm.nih.gov/?term=\%22lep tomeningeal+metastasis $\% 22+\mathrm{AND}+\% 22$ neuroendocrine $+\mathrm{ca}$ rcinoma\%22).

In the present study, irinotecan-gemcitabine was used as the treatment for the LM based on data reported in some publications which found that the irinotecan-gemcitabine combination was effective and well-tolerated as second-line therapy for small-cell lung cancer $(9,10)$.

Only one article was found in the PubMed database using the keywords 'irinotecan' AND 'gemcitabine' AND 'SARS CoV-2', and no patient infected with SARS-CoV-2 was described in that article (12). The sample size of the study by Vidra et al (12) was too small as it only included 11 patients; thus, the result is not conclusive. More clinical trials are required to determine the true relationship between SARS-CoV-2 infection and irinotecan-gemcitabine combination treatment (12).

In May 2021, the patient required intensive care admission due to impaired consciousness and abdominal pain. Analysis of lumbar puncture fluid revealed LC recurrence despite a $\mathrm{PET} / \mathrm{CT}$ scan ruling out metastasis 1 month prior. The patient succumbed to the disease 5 days later.

In conclusion, there are no clear guidelines regarding SmCC treatment at present. Thus, other authors should be encouraged to publish their treatment outcomes regarding SmCC. More clinical trials should be performed to optimize treatment and improve patient outcome.

\section{Acknowledgements}

Not applicable.

\section{Funding}

The publication of this study was supported by AMPLIFON IBERICA SAU.

\section{Availability of data and materials}

The datasets used and/or analyzed during the current study are available from the corresponding author on reasonable request.

\section{Authors' contributions}

AR designed the study; MJMO acquired the data; CB interpreted the data; EG and $\mathrm{AB}$ drafted the manuscript and acquired the data; and FGP analyzed and interpreted the data. All authors have read and approved the final manuscript. EG and $\mathrm{AB}$ confirm the authenticity of all the raw data.

\section{Ethics approval and consent to participate}

Not applicable.

\section{Patient consent for publication}

The patient provided written informed consent regarding the publication of all case details and any accompanying images.

\section{Competing interests}

The authors declare that they have no competing interests.

\section{References}

1. Krishnamurthy A, Ravi P, Vijayalakshmi R and Majhi U: Small cell neuroendocrine carcinoma of the paranasal sinus. Natl J Maxillofac Surg 4: 111-113, 2013.

2. van der Laan TP, Iepsma R, Witjes MJ, van der Laan BF, Plaat BE and Halmos GB: Meta-analysis of 701 published cases of sinonasal neuroendocrine carcinoma: The importance of differentiation grade in determining treatment strategy. Oral Oncol 63: 1-9, 2016.

3. Pointer KB, Ko HC, Brower JV, Witek ME, Kimple RJ, Lloyd RV, Harari PM and Baschnagel AM: Small cell carcinoma of the head and neck: An analysis of the National Cancer Database. Oral Oncol 69: 92-98, 2017.

4. Rosenthal DI, Barker JL Jr, El-Naggar AK, Glisson BS, Kies MS, Diaz EM Jr, Clayman GL, Demonte F, Selek U, Morrison WH, et al: Sinonasal malignancies with neuroendocrine differentiation: patterns of failure according to histologic phenotype. Cancer 101: 2567-2573, 2004.

5. Agoff SN, Lamps LW, Philip AT, Amin MB, Schmidt RA, True LD and Folpe AL: Thyroid transcription factor- 1 is expressed in extrapulmonary small cell carcinomas but not in other extrapulmonary neuroendocrine tumors. Mod Pathol 13: 238-242, 2000.

6. Wani SQ, Dar IA, Khan T and Lone MM: Primary Sino-nasal Neuroendocrine Carcinoma: A Rare Tumor. Cureus 11: e4144, 2019.

7. Iacovou E, Chrysovergis A, Eleftheriadou A, Yiotakis I and Kandiloros D: Neuroendocrine carcinoma arising from the septum. A very rare nasal tumour. Acta Otorhinolaryngol Ital 31: 50-53, 2011.

8. Rivero A and Liang J: Sinonasal small cell neuroendocrine carcinoma: A systematic review of 80 patients. Int Forum Allergy Rhinol 6: 744-751, 2016.

9. Rocha-Lima CM, Herndon JE II, Lee ME, Atkins JN, Mauer A, Vokes E and Green MR; Cancer and Leukemia Group B: Phase II trial of irinotecan/gemcitabine as second-line therapy for relapsed and refractory small-cell lung cancer: Cancer and Leukemia Group B Study 39902. Ann Oncol 18: 331-337, 2007.

10. Schuette W, Nagel S, Juergens S, Bork I, Wollschlaeger B, Schaedlich S and Blankenburg T: Phase II trial of gemcitabine/irinotecan in refractory or relapsed small-cell lung cancer. Clin Lung Cancer 7: 133-137, 2005.

11. National Comprehensive Cancer Network (NCCN): NCCN Guidelines forHead and Neck Cancers V.1.2021. NCCN,Plymouth Meeting, PA, 2021. https://www.nccn. org/guidelines/guidelinesprocess/transparency-process-and-recommendations/GetFile FromFileManager?fileManagerId=11180. Accessed October 18 , 2021.

12. Vidra R, Bodea R, Mercea V and Nemes A: Challenges of pancreatic cancer chemotherapy in the COVID-19 era. J Gastrointestin Liver Dis 29: 273-275, 2020. 